\title{
ALAT MONITORING DAN PEMBATAS DAYA LISTRIK RUMAH TANGGA BERBASIS ARDUINO MEGA 2560
}

\author{
${ }^{1}$ Rega Sundawa Putra, ${ }^{2}$ Massus Subekti, ${ }^{3}$ Nur Hanifah Yuninda. \\ 1,2,3 Pendidikan Teknik Elektro, Fakultas Teknik, Universitas Negeri Jakarta. \\ ${ }^{1}$ E-mail :regasundawaputra@gmail.com
}

\begin{abstract}
This research aims to create a monitoring and power strip loads home based arduino mega 2560. This research uses experimental method and was done in the mechanical workshop of Electrical Engineering, Faculty of Engineering, State University of Jakarta in September 2015 until January 2016. This prototype uses an Arduino Mega 2560 with the programming language C simplified to the IDE 1.6.5 software. Input equipment consists of 4 Current Sensor ACS 712, 1 Voltage Sensor, 1 keypad 4x4. Current Sensor ACS 712 is used on prototype for the current reading it. The Voltage Sensor is used on prototype to read the voltage coming out of PLN. Keypad $4 x 4$ is used on prototype to set the usage limit load. Testing tool that is compared with avometer digital heles ux-838TR for measuring voltage and power meter Pilot SPM91 measuring amount load and current. The result of differences in measurement for light load $1 \%$, ironing $8 \%$, hairdryer $6 \%$. From the monitoring and power strip loads home based arduino mega 2560, the tools and system can work in accordance with the system designed

Keywords: Arduino Mega 2560, Current Sensor ACS 712, Voltage Sensor, Driver Relay, keypad 4x4, electrical load
\end{abstract}

\begin{abstract}
Abstrak
Penelitian ini bertujuan membuat prototipe pengawasan dan pengendalian beban listrik rumah tangga berbasis arduino mega 2560. Penelitian ini menggunakan metode eksperimen dan dilaksanakan di Laboratorium Teknik Instalasi Listrik Teknik Elektro, Fakultas Teknik, Universitas Negeri Jakarta pada bulan September 2015 sampai Januari 2016. Prototipe ini menggunakan Arduino Mega 2560 dengan bahasa pemrograman yaitu bahasa $\mathrm{C}$ yang disederhanakan dengan software IDE 1.6.5. Peralatan input terdiri dari 4Sensor Arus ACS 712, 1 Sensor Tegangan, 1 Keypad 4x4. Sensor Arus ACS 712 digunakan pada prototipe untuk membaca arus yang terpakai. Sensor Tegangan digunakan pada prototipe untuk membaca tegangan yang keluar dari sumber PLN. Keypad digunakan pada prototipe untuk mengatur batas pemakaian beban. Pengujian alat yaitu dibandingkan dengan avometer digital heles ux-838TR untuk mengukur tegangan dan alat ukur power meter Pilot SPM91 untuk mengukur jumlah watt dan arus. Hasil perbedaaan pengukuran untuk beban lampu sebesar $1 \%$, setrika $8 \%$, hairdryer 6\%.Dari hasil penelitian alat monitoring dan pembatas daya listrik rumah tangga berbasis Arduino Mega 2560, alat dan sistem dapat bekerja sesuai dengan yang dirancang.
\end{abstract}

Kata Kunci :Arduino Mega 2560, Sensor ACS 712, Sensor Tegangan, Driver Relay, keypad 4x4 dan beban listri

\section{PENDAHULUAN}

Perkembangan teknologi telah banyak membantu dalam meningkatkan kualitas dan kesejahteraan hidup manusia. Seiring dengan perkembangan tersebut, menghadirkan beberapa teknologi yang mampu diterapkan dalam kehidupan masyarakat luas untuk membantu dalam setiap aktifitas manusia. Salah satu sistemnya yaitu alat yang mampu memonitoring penggunaan energi listrik. Alat monitoring penggunaan energi listrik adalah suatu teknologi yang mampu memonitoring penggunaan energi listrik serta kinerjanya menjadi hal yang dibutuhkan dalam meningkatkan kenyamanan bagi penggunanya.

Penggunaan energi listrik dapat dilakukan dengan melalui jalur stop kontak dan melalui saklar. Sedangkan untuk membatasi penggunaan jumlah daya yang digunakan dalam suatu instalasi pada umumnya digunakan alat Miniature Circuit Breaker (MCB). MCB akan memutuskan arus listrik secara seketika daya yang digunakan dalam suatu instalasi jika melewati batas daya yang tertera pada MCB. Terjadinya pemutusan seketika tersebut akan menyebabkan penurunan kualitas peralatanperalatan listrik, serta dapat menimbulkan terjadinya peningkatan jumlah penggunaan daya ketika proses nyala-mati. Oleh karena itu diperlukan suatu sistem yang mampu memantau penggunaan daya agar dapat mencegah terjadinya pemutusan aliran listrik secara seketika. Selain dapat membatasi penggunaan jumlah daya, sistem juga harus mampu 
memonitoring seberapa besar penggunaan daya yang terpakai

Ada 2 jenis sistem pengendalian, yaitu sistem pengendalian loop terbuka dan sistem pengendalian loop tertutup. Berdasarkan hal tersebut, penulis akan memakai jenis sistem pengendalian loop tertutup karena sistem pengendalian loop tertutup adalah suatu sistem yang tindakan pengendaliannya tergantung pada keluarannya. Keluaran sistem ini berpengaruh langsung terhadap aksi kendali. Yang berupaya untuk mempertahankan keluaran sehingga sama bahkan hampir sama dengan masukan acuan walaupun terdapat gangguan pada sistem. Jadi sistem ini adalah sistem kendali berumpan balik, dimana kesalahan penggerak adalah selisih antara sinyal masukan dan sinyal umpan balik (berupa sinyal keluaran dan turunannya) yang diteruskan ke pengendali / controller sehingga melakukan aksi terhadap proses untuk memperkecil kesalahan dan membuat agar keluaran mendekati harga yang diinginkan. Maka akan dibuatlah Alat monitoring dan pembatas daya beban listrik rumah tangga berbasis arduino mega 2560.

\section{METODE}

Metode penelitian dapat diartikan sebagai langkah-langkah penelitian suatu produk yang akan dikembangkan atau dilakukan. Metode penelitian yang digunakan dalam menyelesaikan penelitian ini adalah menggunakan metode Eksperimen Laboratorium (Laboratorium Experiment). Metode yang digunakan dapat dilihat tahapannya pada Gambar1 berikut.

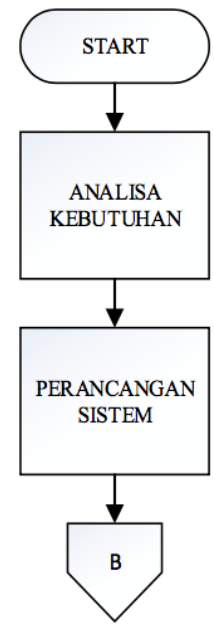

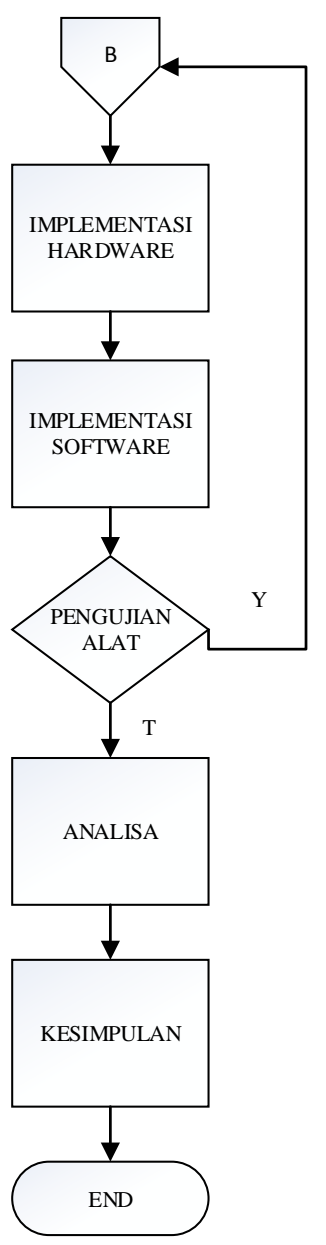

Gambar 1 Metode dan Alur Penelitian

Gambar 2 dan Gambar 3 ini adalah bentuk rancangan prototipe buatan.

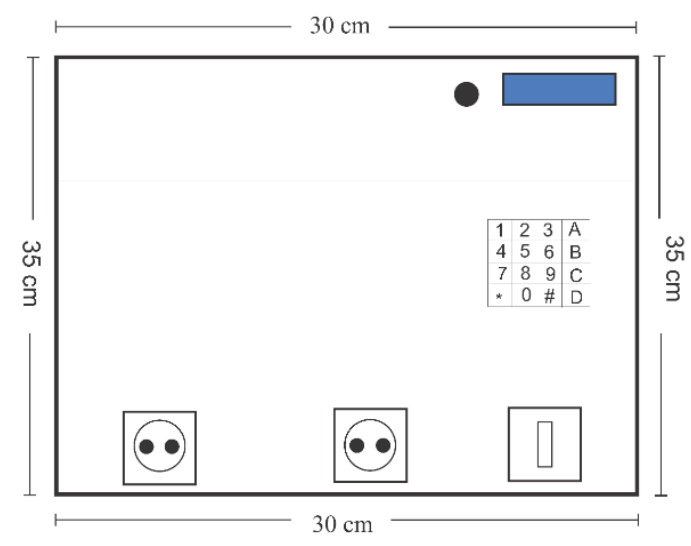

Gambar 2 desain prototipe tampak atas 


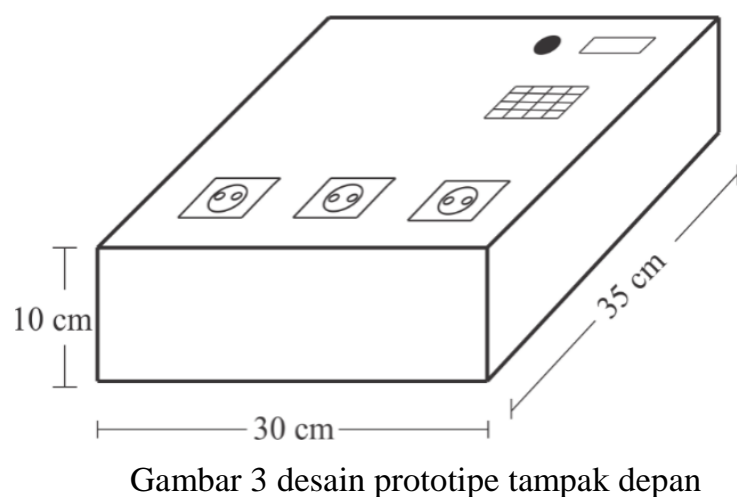

Sistem kerja prototipe pada gambar 4 .

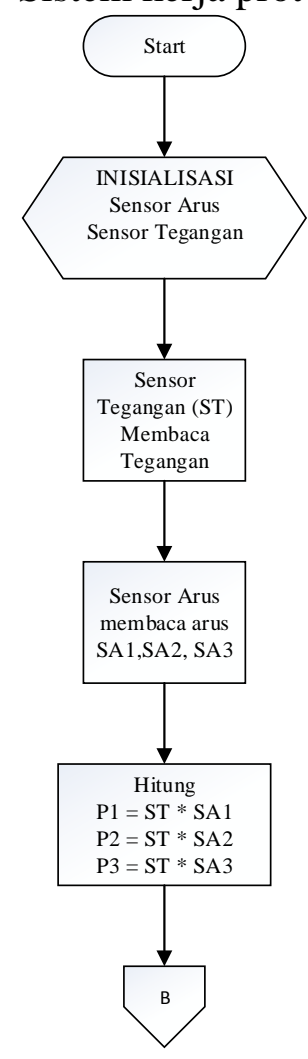

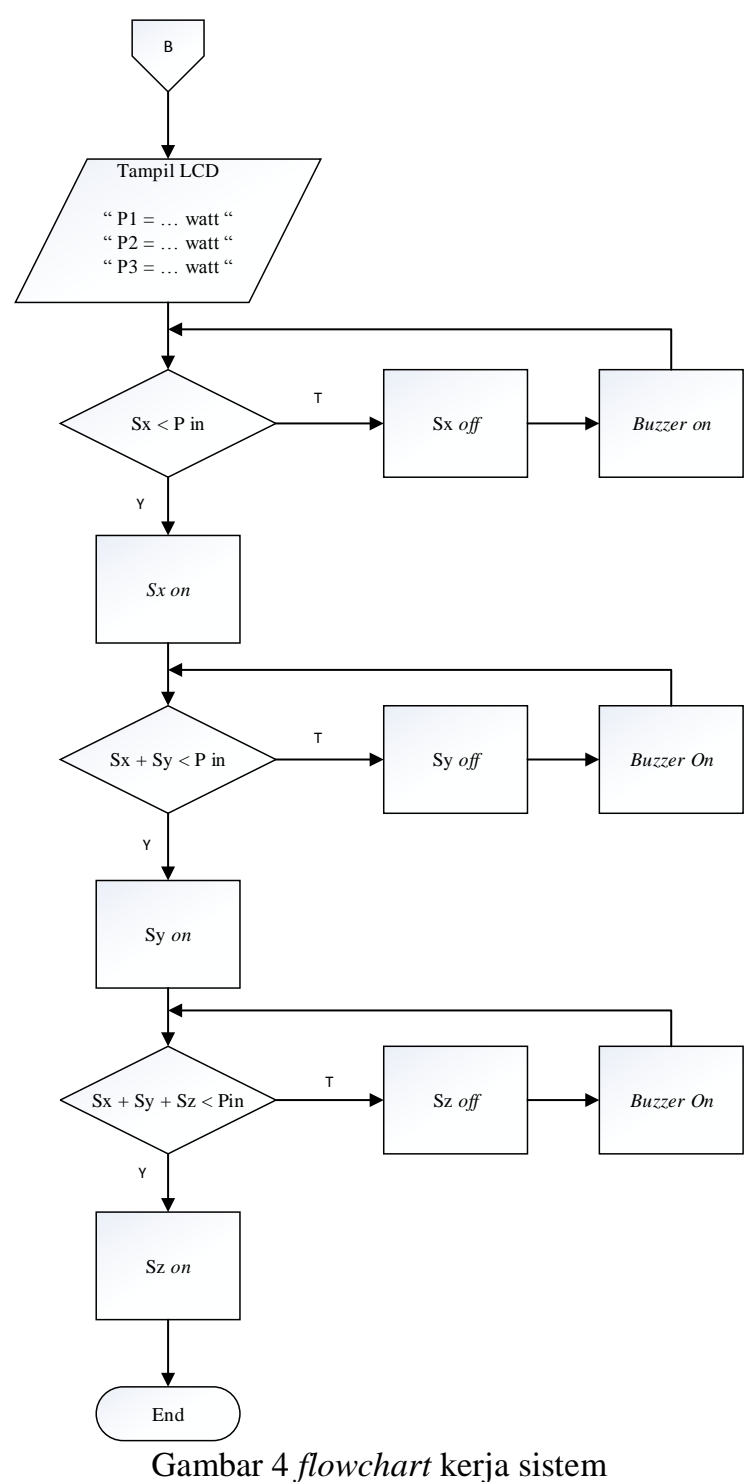

\section{HASIL DAN PEMBAHASAN}

\section{Hasil Pengukuran Tegangan}

Hasil pengujian tegangan meliputi tegangan masuk PLN, tegangan keluar transformator, tegangan keluar transistor 7808. Hasil pengujian dapat dilihat pada tabel 1

Tabel 1 Hasil Pengujian Tegangan

\begin{tabular}{cccc}
\hline & Tegangan in & Tegangan out & Tegangan out \\
No. & PLN & Transformator & 7808 \\
1 & 213 Volt & 11 Volt & 8 Volt \\
\hline
\end{tabular}

\section{Hasil Pengukuran Tegangan Sensor Arus ACS} 712

Hasil pengukuran meliputi Sensor Arus ACS 712 1, 2, 3. Hasil pengukuran dapat dilihat pada tabel 2 . 
Tabel 2 Hasil Pengukuran Tegangan Out Sensor Arus ACS 712

\begin{tabular}{lccc}
\hline No & Jenis Sensor & $\begin{array}{c}\text { Kriteria Pengujian } \\
\text { Tegangan out }\end{array}$ & $\begin{array}{c}\text { Ha sil Pengukuran } \\
\text { Tegangan out }\end{array}$ \\
\hline & & & \\
1. & Sensor ACS 1 & 2,5 VDC & 2,44 VDC \\
2. & Sensor ACS 2 & 2,5 VDC & 2,45 VDC \\
3. & Sensor ACS 3 & 2,5 VDC & 2,46 VDC \\
4. & Sensor ACS 4 & 2,5 VDC & 2,46 VDC \\
\hline
\end{tabular}

\section{Hasil Pegujian Sensor Arus ACS 712}

Hasil pengujian sensor arus ACS 712 dengan beban dan dibandingkan dengan alat ukur power meter Pilot SPM91. Hasil pengujian dapat dilihat pada tabel 3, 4, 5 .

Tabel 3 Hasil Pegujian Sensor Arus ACS 712 (1) Beban Lampu 100 watt

\begin{tabular}{cccc}
\hline No & Alat Ukur & Percobaan & Error \\
\hline 1 & $0,41 \mathrm{~A}$ & $0,41 \mathrm{~A}$ & $0 \%$ \\
2. & $0,41 \mathrm{~A}$ & $0,41 \mathrm{~A}$ & $0 \%$ \\
3. & $0,41 \mathrm{~A}$ & $0,40 \mathrm{~A}$ & $2 \%$ \\
4. & $0,41 \mathrm{~A}$ & $0,40 \mathrm{~A}$ & $2 \%$ \\
5. & $0,41 \mathrm{~A}$ & $0,41 \mathrm{~A}$ & $0 \%$ \\
6. & $0,41 \mathrm{~A}$ & $0,41 \mathrm{~A}$ & $0 \%$ \\
7. & $0,41 \mathrm{~A}$ & $0,40 \mathrm{~A}$ & $2 \%$ \\
8. & $0,41 \mathrm{~A}$ & $0,40 \mathrm{~A}$ & $2 \%$ \\
9. & $0,41 \mathrm{~A}$ & $0,40 \mathrm{~A}$ & $2 \%$ \\
10. & $0,41 \mathrm{~A}$ & $0,41 \mathrm{~A}$ & $0 \%$ \\
& & & $1 \%$ \\
\hline
\end{tabular}

Tabel 4 Hasil Pegujian Sensor Arus ACS 712 (2) Beban Setrika 300 watt

\begin{tabular}{cccc}
\hline No & Alat Ukur & Percobaan & Error \\
\hline 1 & $1,39 \mathrm{~A}$ & $1,27 \mathrm{~A}$ & $8 \%$ \\
2. & $1.39 \mathrm{~A}$ & $1,27 \mathrm{~A}$ & $8 \%$ \\
3. & $1.39 \mathrm{~A}$ & $1,27 \mathrm{~A}$ & $8 \%$ \\
4. & $1,38 \mathrm{~A}$ & $1,26 \mathrm{~A}$ & $8 \%$ \\
5. & $1,38 \mathrm{~A}$ & $1,26 \mathrm{~A}$ & $8 \%$ \\
6. & $1,38 \mathrm{~A}$ & $1,26 \mathrm{~A}$ & $8 \%$ \\
7. & $1,39 \mathrm{~A}$ & $1,27 \mathrm{~A}$ & $8 \%$ \\
8. & $1,39 \mathrm{~A}$ & $1,27 \mathrm{~A}$ & $8 \%$ \\
9. & $1,38 \mathrm{~A}$ & $1,26 \mathrm{~A}$ & $8 \%$ \\
10. & $1,38 \mathrm{~A}$ & $1,26 \mathrm{~A}$ & $8 \%$ \\
& & & $8 \%$ \\
\hline
\end{tabular}

Tabel 5 Hasil Pegujian Sensor Arus ACS 712 (3) Beban Hairdyer 750 watt

\begin{tabular}{cccc}
\hline No & Alat Ukur & Percobaan & Error \\
\hline 1 & $3,54 \mathrm{~A}$ & $3,30 \mathrm{~A}$ & $6 \%$ \\
2. & $3,54 \mathrm{~A}$ & $3,30 \mathrm{~A}$ & $6 \%$ \\
3. & $3,54 \mathrm{~A}$ & $3,30 \mathrm{~A}$ & $6 \%$ \\
4. & $3,54 \mathrm{~A}$ & $3,30 \mathrm{~A}$ & $6 \%$ \\
5. & $3,54 \mathrm{~A}$ & $3,30 \mathrm{~A}$ & $6 \%$ \\
6. & $3,56 \mathrm{~A}$ & $3,32 \mathrm{~A}$ & $6 \%$ \\
7. & $3,56 \mathrm{~A}$ & $3,32 \mathrm{~A}$ & $6 \%$ \\
8. & $3,55 \mathrm{~A}$ & $3,31 \mathrm{~A}$ & $6 \%$ \\
9. & $3,55 \mathrm{~A}$ & $3,31 \mathrm{~A}$ & $6 \%$ \\
10. & $3,55 \mathrm{~A}$ & $3,31 \mathrm{~A}$ & $6 \%$ \\
& & & $6 \%$ \\
\hline
\end{tabular}

\section{Hasil Pengujian Sensor Arus ACS 712 1, 2, 3}

Hasil pengujian meliputi pengukuran yang membandingkan hasil antara sensor arus ACS 712 1, 2, 3 yang tertera pada alat dan menggunakan beban lampu 100 watt yang dilakukan sebanyak 5 kali. Pengujian dapat dilihat pada tabel 6

Tabel 6 Hasil pengujian sensor sensor arus ACS

\begin{tabular}{cccc}
\hline \multirow{2}{*}{ No } & $\begin{array}{c}\text { ACS 712 (1) } \\
\text { (A) }\end{array}$ & $\begin{array}{c}\text { ACS 712 (2) } \\
(\mathrm{A})\end{array}$ & $\begin{array}{c}\text { ACS 712 (3) } \\
(\mathrm{A})\end{array}$ \\
\hline 1 & 0,41 & 0,40 & 0,42 \\
2. & 0,40 & 0,40 & 0,42 \\
3. & 0,41 & 0,39 & 0,42 \\
4. & 0,41 & 0,40 & 0,42 \\
5. & 0,40 & 0,40 & 0,42 \\
\hline
\end{tabular}

\section{Hasil Pengujian Sensor Tegangan}

Hasil pengujian sensor tegangan dan dibandingkan dengan menggunakan avometer digital heles ux-838TR. Hasil pengujian dapat dilihat pada tabel 7 .

Tabel 7Hasil pengujian sensor tegangan

\begin{tabular}{cccc}
\hline No & Alat Ukur & Percobaan & Kesalahan \\
\hline 1 & $213 \mathrm{~V}$ & $224 \mathrm{~V}$ & $5 \%$ \\
2. & $213 \mathrm{~V}$ & $224 \mathrm{~V}$ & $5 \%$ \\
3. & $212 \mathrm{~V}$ & $224 \mathrm{~V}$ & $6 \%$ \\
4. & $211 \mathrm{~V}$ & $223 \mathrm{~V}$ & $6 \%$ \\
5. & $211 \mathrm{~V}$ & $223 \mathrm{~V}$ & $6 \%$ \\
6. & $207 \mathrm{~V}$ & $215 \mathrm{~V}$ & $3 \%$ \\
7. & $213 \mathrm{~V}$ & $224 \mathrm{~V}$ & $5 \%$ \\
8. & $213 \mathrm{~V}$ & $224 \mathrm{~V}$ & $5 \%$ \\
\hline
\end{tabular}

\section{Hasil Titik Pengujian}

Hasil titik pegujian meliputi pengukuran relay 1 , relay 2 , relay 3 , sensor acs 1,2 dan 3 yaitu dengan menggunakan avometer digital heles ux-838TR. Adapun gambar titik pengujian dapat dilihat pada gambar 5 , dan hasil pengujian dapat dilihat pada tabel 8, 9 dan 10 .

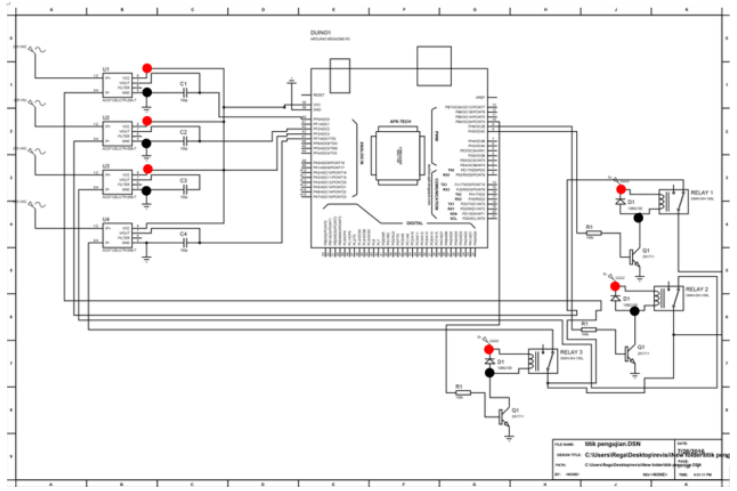

Gambar 5 Titik Pengujian Relay dan Sensor ACS 712 Tabel 8 Hasil Titik Pengujian Relay

\begin{tabular}{ccc}
\hline No & Relay & Tegangan \\
\hline 1 & Relay 1 & 3,97 Volt \\
2. & Relay 2 & 3,66 Volt \\
3. & Relay 3 & 3,40 Volt \\
\hline
\end{tabular}


Tabel 9. Hasil Titik Pengujian Sensor ACS 712

\begin{tabular}{ccc}
\hline No & $\begin{array}{c}\text { Sensor ACS } \\
712\end{array}$ & Tegangan \\
\hline 1 & Sensor ACS 1 & 4,36 Volt \\
2. & Sensor ACS 2 & 4,33 Volt \\
3. & Sensor ACS 3 & 4,43 Volt \\
\hline
\end{tabular}

\section{Hasil Pengujian Perangkat Lunak (Software)}

Hasil pengujian prototipe meliputi data sheet beban, urutan beban, hasil pengujian beban sensor arus, sensor tegangan, tampilan LCD, dan kondisi stop kontak. Hasil pengujian dapat dilihat pada tabel 8.

Tabel 10 Hasil Pengujian Prototipe

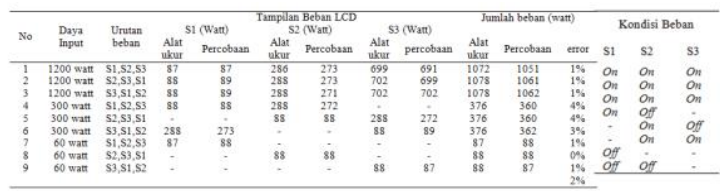

Berdasarkan pengujian keseluruhan yang telah dilakukan diketahui bahwa Arduino Mega 2560, Sensor ACS 712, Sensor Tegangan, Driver Relay, Liquid Crystal Display (LCD), keypad $4 \times 4$ pada prototipe pengawasan dan pengendalian beban listrik rumah tangga dapat berfungsi sesuai perencanaan. Saat pengujian prototipe pengawasan dan pengendalian beban listrik rumah tangga, terdapat beberapa kekurangan yang kadang menyebabkan kontrol tidak normal, yaitu terjadinaik turunnya arus dan tegangan sehingga menyebabkan perhitungan jumlah daya naik turun. Sehingga menyebabkan terkadang sistem kurang bekerja dengan baik.

\section{KESIMPULAN DAN SARAN \\ Kesimpulan}

Berdasarkan hasil penelitian yang telah dilakukan melalui tahap perencanaan, perancangan, pembuatan dan pengujian maka dapat diambil kesimpulan sebagai berikut:

1. Perancangan dan pembuatan Alat Monitoring dan Pembatas Daya Listrik Rumah Berbasis Arduino Mega 2560 berhasil tercapai.

2. Monitoring penggunaan beban listrik keseluruhan dapat dilhat melalu LCD 20x4.

3. Pembatas daya listrik berhasil di setting dengan menggunakan keypad 4x4.
4. Saklar otomatis menggunakan relay yang disambungkan dengan stop kontak.

5. Program untuk menjalankan keseluruhan sistem yaitu dengan menggunakan software IDE 1..6.5

6. Error pembacaan antara percobaan dan alat ukur power meter Pilot SPM91 pada beban lampu 100 watt sebesar $1 \%$, pada beban setrika 300 watt sebesar $8 \%$, sedangkan pada beban hairdryer sebesar $6 \%$.

\section{Saran}

Dalam pembuatan alat monitoring dan pembatas beban listrik rumah tangga berbasis arduino Mega 2560 ini, penulis menyadari masih banyak kekurangan dan kelemahan pada prototipe tersebut. Diantaranya adalah sebagai berikut:

1. Bagian dalam prototipe masih terkesan kurang rapih banyaknya kabel serta komponen yang sulit untuk dibuat rapih. Oleh karena itu perlu dibuat prototipe dengan ukuran yang lebih besar serta disediakannya tempat khusus rangkaian elektronikanya..

2. Untuk penelitian selanjutnya dapat mengembangkan desain alat agar lebih menarik.Mengembangkan desain alat agar lebih menarik.

\section{DAFTAR PUSTAKA}

Achzab, Asharudin. 2015. Ac voltage sensor. http://www.jualarduino.com/single-phaseac-voltage-sensor-module/. Diakses 15 Oktober 2015.

Fahmizal. 2015. Arduino Mega 2560. http://www.hendriono.com/blog/post/menge nal-arduino-mega2560. Diakses 14

November 2015.

Fakultas Teknik. 2009. Buku Pedoman Skripsi / Komprehensif/Karya Inovatif (S1). Jakarta: Fakultas Teknik, Universitas Negeri Jakarta.

Hermawan, Rudy. 2015. ACS712 Current Sensor. http://i00.i.aliimg.com/wsphoto/v0/3231558 0378/ACS712-Current-Sensor-ModuleDetector-20-Amps-font-b-Amperage-b-fontRange.jpg. Diakses 15 Oktober 2015 
Indrahaja. 2012. Pengertian Buzzer. https://indrahaja.wordpress.com/2012/01/07/ pengertian-buzzer diakses 15 Oktober 2015

Kadir, Abdul. 2012. Panduan Praktis

Mempelajari Aplikasi Mikrokontroler dan Pemrogramannya menggunakan Arduino. Yogyakarta: ANDI 